\title{
PENERAPAN DATA MINING UNTUK PENGELOMPOKAN PENDUDUK KURANG MAMPU DESA SAMBIREJO TIMUR DENGAN ALGORITMA K-MEDOIDS (STUDI KASUS KANTOR KEPALA DESA SAMBIREJO TIMUR)
}

\author{
Jefri Arianto \\ Program Studi Teknik Informatika, STMIK Budi Darma, Medan, Indonesia \\ Email: Jefririanto30@gmail.com
}

\begin{abstract}
Abstrak
Desa Sambirejo Timur menjadi salah satu percontohan yang berhasil dalam pengelolaan data desa. Pengelolaan data desa tersebut sebagai dasar dalam perencanaan pembangunan desa, sehingga tepat sasaran sesuai potensi desa dan kebutuhan masyarakat. Sumber data dari Kantor Kepala Desa Sambirejo Timur tahun 2018 menunjukkan bahwa jumlah penduduk kurang mampu di Desa Sambirejo Timur tergolong tinggi, sejumlah penduduk kurang lebih 25.936 jiwa dan kurang lebih 7000 kepala keluarga dengan persentase penduduk kurang mampu mencapai 12,5\%. Berdasarkan angka tersebut terlihat masih banyak penduduk Desa Sambirejo Timur yang kurang mampu secara umum. Berdasarkan kondisi tersebut perlu dibangun sistem clustering atau pengelompokan data untuk membantu pemerintah desa dalam pengelompokan penduduk kurang mampu sehingga bantuan dari pemerintah desa dapat tersalurkan dengan tepat. Penelitian ini menggunakan metode K-Medoids dalam clustering penduduk kurang mampu.
\end{abstract}

Kata Kunci : Penduduk Kurang Mampu, K-Medoids, Visual Basic Net 2008.

Abstract

The village of East Sambirejo became one of the successful pilots in village data management. Village data management is the basis in village development planning, so that it is right on target according to the village's potential and community needs. Data sources from the Office of the Village Head of East Sambirejo in 2018 show that the number of underprivileged people in the Village of East Sambirejo is relatively high, with a total population of approximately 25,936 people and approximately 7,000 households with a percentage of the underprivileged population reaching $12.5 \%$. Based on this number, it can be seen that there are still many people in the village of East Sambirejo who are generally poor. Based on these conditions, it is necessary to build a clustering system or grouping data to assist the village government in grouping underprivileged populations so that assistance from the village government can be distributed appropriately. This study uses the K-Medoids method in clustering underprivileged populations.

Keywords: Underprivileged Population, K-Medoids, Visual Basic Net 2008

\section{PENDAHULUAN}

Teknologi berkembang pesat, segala sesuatu yang akan dikerjakan harus cepat dan tepat. Maka dari itu hampir semua orang di dunia menyadari bahwa pentingnya peranan komputer saat sekarang ini. Komputer merupakan sarana yang tepat untuk mempermudah segala urusan disegala bidang, terutama di instansi pemerintahan atau disebuah perusahaan. Teknologi bukan hanya berkembang dalam bidang pemerintah saja tetapi dalam segala bidang. Misalnya, bidang politik, ekonomi, seni, budaya, dan bahkan didunia pendidikan. Kemajuan teknologi adalah sesuatu yang tidak bisa kita hindari, karena kemajuan teknologi akan berjalan sesuai dengan ilmu pengetahuan. Setiap inovasi yang diciptakan untuk memberikan manfaat positif bagi kehidupan manusia. Khusus dalam bidang teknologi informasi sudah menikmati banyak manfaat yang dibawa oleh inovassi-inovasi yang telah dihasilkan dalam dekade terakhir ini.

Kantor Kepala Desa Sambirejo Timur sebagai pusat database penduduk yang mencakup beberapa wilayah Kecamatan Percut Sei Tuan, selalu mendata setiap masyarakat yang belum terdaftar pada suatu Kecamatan Percut Sei Tuan. Dalam melaksanakan tugasnya, Kantor Kepala Desa Sambirejo Timur menerapkan sistem pusat wilayah pelayanan dari beberapa Kecamatan Percut Sei Tuan sebagai upaya percepatan pelayanan kepada masyarakat. Kantor Kepala Desa Sambirejo Timur merupakan unsur pelaksana Pemerintah Daerah yang dipimpin oleh Kepala Dinas yang berada dibawah dan bertanggung jawab kepada Bupati Deli Serdang melalui Sekretaris Daerah Kabupaten yang dibentuk berdasarkan Perda No. 5 tahun 2007.

Desa Sambirejo Timur menjadi salah satu percontohan yang berhasil dalam pengelolaan data desa. Pengelolaan data desa tersebut sebagai dasar dalam perencanaan pembangunan desa, sehingga tepat sasaran sesuai potensi desa dan kebutuhan masyarakat. Sekretaris Desa Sambirejo Timur menjelaskan bahwa proses pengelolaan data yang dilakukan melibatkan masyarakat secara langsung yang dimulai dari perekrutan tenaga pencacah, melaksanakan pelatihan yang melibatkan pendamping, kemudian masyarakat melakukan pendataan secara langsung dan Kepala Desa melakukan monitoring. Selanjutnya data di verifikasi untuk dimasukkan dan diolah, sehingga bisa mendapatkan data layanan sosial dasar, seperti data jumlah anak putus sekolah, data sanitasi dan air bersih, cakupan imunisasi, pengobatan gratis bagi yang kurang mampu dan lain-lain. Dengan pendataan seperti itu lebih mudah menentukan program pemberdayaan dan lebih tepat sasaran untuk mengetahi masyarakat dengan kriteria seperti apa yang berhak mendapatkan bantuan tersebut.

\section{TEORITIS}




\subsection{Data Mining}

Penggalian data (bahasa Inggris: data mining) adalah ekstraksi pola yang menarik dari data dalam jumlah besar. Suatu pola dikatakan menarik apabila pola tersebut tidak sepele, implisit, tidak diketahui sebelumnya, dan berguna. Pola yang disajikan haruslah mudah dipahami, berlaku untuk data yang akan diprediksi dengan derajat kepastian tertentu, berguna, dan baru. Penggalian data memiliki beberapa nama alternatif, meskipun definisi eksaknya berbeda, seperti KDD (Knowledge Discovery in Database), analisis pola, arkeologi data, pemanenan informasi, dan intelegensia bisnis. Penggalian data diperlukan saat data yang tersedia terlalu banyak (misalnya data yang diperoleh dari sistem basis data perusahaan, e-comerce, data saham, data sensus dan data bioinformatika), tetapi tidak tahu pola apa yang bisa didapatkan. Data mining sangat perlu dilakukan terutama dalam mengelola data yang sangat besar untuk untuk memudahkan aktivitas recording suatu transaksi dan untuk proses data worehousing agar dapat memberikan informasi yang akurat bagi penggunanya alasan utama mengapa data mining sangat menarik perhatian industri informasi dalam beberapa tahun belakangan ini adalah karena tersedianya data dalam jumlah yang sangat besar dan semakin besarnya kebutuhan untuk mengubah data tersebut menjadi informasi dan pengetahuan yang berguna karena sesuai fokus bidang ilmu yaitu melakukan kegiatan mengekstrasi atau menambang pengetahuan dari data yang berukuran/berjumlah besar, informasi inilah yang nantinya sangat berguna untuk pengembangan.

Data mining adalah proses analitik yang dirancang untuk memeriksa sejumlah data yang besar dalam mencari suatu pengetahuan tersembunyi yang berharga dan konsisten [2]. Tujuan dari data mining yaitu mencari trend atau pola yang diinginkan dalam database besar untuk membantu dalam pengambilan keputusan pada waktu yang akan datang.

\subsection{Algoritma K-Medoids Clustering}

Algoritma K-Medoids atau Partitioning Around Medoids (PAM) adalah algoritma clustering yang mirip dengan K-Means. Perbedaan dari kedua algoritma ini yaitu algoritma K-Medoids atau PAM menggunakan objek sebagai perwakilan (medoid) sebagai pusat cluster untuk setiap cluster, sedangkan K-Means menggunakan nilai ratarata (mean) sebagai pusat cluster [5]. Algoritma K-Medoids memiliki kelebihan untuk mengatasi kelemahan pada pada algoritma K-Means yang sensitive terhadap noise dan outlier, dimana objek dengan nilai yang besar yang memungkinkan menyimpang pada dari distribusi data. Kelebihan lainnya yaitu hasil proses clustering tidak bergantung pada urutan masuk dataset. Langkah-langkah algoritma K-Medoids:

1. Inisialisasi pusat clustersebanyak $\mathrm{k}(\mathrm{jumlah}$ cluster)

2. Alokasikan setiap data (objek) ke clusterterdekat menggunakan persamaan

ukuran jarak Euclidian Distance dengan persamaan:

$(x, y)=\|x-y\|=\sqrt{ } \sum(x i-y i)^{2} n i=\ldots$

3. Pilih secara acak objek pada masing-masing cluster sebagai kandidat medoidbaru

4. Hitung jarak setiap objek yang berada pada masing-masing cluster dengan kandidat medoidbaru.

5. Hitung total simpangan (S)dengan menghitungnilai total distancebaru -total distancelama. Jika $S<0$, maka tukar objek dengan data cluster untuk membentuk sekumpulan kobjek baru sebagai medoid.

6. Ulangi langkah 3 sampai 5 hingga tidak terjadi perubahan medoid, sehingga didapatkan cluster beserta anggota cluster masing-masing.

Clustering merupakan suatu proses pengelompokkan record, observasi, atau mengelompokkan kelas yang memiliki kesamaan objek [5]. Perbedaan klustering dengan klasifikasi yaitu tidak adanya variabel target dalam melakukan pengelompokan pada proses clustering. Clustering sering dilakukan sebagai langkah awal dalam proses data mining. Terdapat banyak algoritma clustering yang telah digunakan oleh peneliti sebelumnya seperti K-Means, Improved K-Means, Fuzzy C-Means, DBSCAN, K-Medoids (PAM), CLARANS dan Fuzzy Substractive.Setiap algortima memiliki kelebihan dan kekurangan masing-masing, namun prinsip algoritma sama, yaitu meelompokkan data sesuaidengan karakteristik dan mengukur jarak kemiripan antar data dalam satu kelompok.

\subsection{Pendapatan Penduduk}

Memajukan perekonomian di desa adalah tugas yang sangat penting. Hal ini dikarenakan mayoritas penduduk Indonesia adalah masyarakat pedesaan. Dalam memutar roda perekonomian, jelas ada perbedaan yang jauh antara masyarakat desa dengan masyarakat kota. Ekonomi masyarakat desa ditopang oleh beberapa sektor pendapatan. Semua sektor inilah yang harus ditingkatkan agar ekonomi masyarakat desa bisa maju dan berkembang. Pada umumnya, ada 4 sektor yang menopang ekonomi masyarakat di desa Sambirejo Timur Tembung. Jika kelima sektor ini mengalami kendala, maka penurunan pendapatan ekonomi.

Berikut ini keempat sektor tersebut dan penjelasannya:

\section{Sektor Pertanian}

Sektor pertanian adalah bidang utama yang menjadi mata pencarian penduduk Desa Sambirejo Timur Tembung. Desa memberikan peranan yang sangat vital sebagai pertahanan pangan suatu negara. Kemajuan ekonomi dalam sektor pertanian akan menghindarkan negara dari kondisi impor. Hasil dari pertanian ini beragam mulai dari padi, sayuran, sawit dan karet. 
2. Sektor Peternakan

Selain bergantung pada sektor pertanian, ekonomi masyarakat Desa Sambirejo Timur Tembung juga bergantung pada sektor peternakan. Ada banyak peternakan yang ada di desa-desa. Semua peternakan ini biasanya masih bersifat konvensional. Beberapa binatang diternak di desa seperti kambing, sapi, ayam, bebek dan beberapa jenis ikan tertentu.

3. Sektor Industri Kreatif

Industri kreatif nyatanya juga menjadi pendapatan ekonomi masyarakat di Desa Sambirejo Timur Tembung. Hal ini dibuktikan dengan banyaknya usaha dalam bidang kreatif di Indonesia. Industri kreatif ini biasanya akan menghasilan sebuah karya kerajinan tangan. Contoh hasil dari industri ini seperti kursi rotan, tas dari bambu, sarung tenun dan beberapa kerjinan tangan lainnya.

4. Sektor Perikanan

Sektor perikanan sama dengan sektor peternakan. Pada sektor ini, masyarakat Desa Sambirejo Timur Tembung banyak yang membudidayakan ikan, misalnya ikan lele, ikan mas, ikan nila dan ikan cupang.

\section{ANALISA DAN PEMBAHASAN}

\subsection{Analisa Masalah}

Desa Sambirejo Timur Tembung menjadi salah satu percontohan yang berhasil dalam pengelolaan data desa. Pengelolaan data desa tersebut sebagai dasar dalam perencanaan pembangunan desa, sehingga tepat sasaran sesuai potensi desa dan kebutuhan masyarakat. Sekretaris Desa Sambirejo Timur Tembung menjelaskan bahwa proses pengelolaan data yang dilakukan melibatkan masyarakat secara langsung yang dimulai dari perekrutan tenaga pencacah, melaksanakan pelatihan yang melibatkan pendamping, kemudian masyarakat melakukan pendataan secara langsung dan Kepala Desa melakukan monitoring. Selanjutnya data di verifikasi untuk dimasukkan dan diolah, sehingga bisa mendapatkan data layanan sosial dasar, seperti data jumlah anak putus sekolah, data sanitasi dan air bersih, cakupan imunisasi, pengobatan gratis bagi yang kurang mampu dan lain-lain. Dengan pendataan seperti itu lebih mudah menentukan program pemberdayaan dan lebih tepat sasaran untuk mengetahi masyarakat dengan kriteria seperti apa yang berhak mendapatkan bantuan tersebut. Maka penulis menggunakan algoritma K-Medoids untuk membantu menyelesaikan permasalahan pengelompokan penduduk kurang mampu.

Rumus K-Medoids :

Keterangan :

$$
(x, y)=\|x-y\|=\sqrt{ } \sum(x i-y i)^{2} n i=\ldots
$$

$\boldsymbol{x} \quad$ : Titik data pertama.

$\boldsymbol{y} \quad$ : Titik data kedua.

n : Jumlah karakteristik (atribut) dalm terminologi data mining.

$\boldsymbol{d}(\boldsymbol{x}, \boldsymbol{y}) \quad$ : Euclidian distance yaitu jarak antara data pada titik $\boldsymbol{x}$ dan titik $\boldsymbol{y}$ menggunakan kalkulai matematika.

Langkah-langkah metode K-Medoids :

1. Inisialisasi pusat cluster sebanyak $\mathrm{k}(\mathrm{jumlah}$ cluster)

2. Alokasikan setiap data (objek) ke cluster terdekat menggunakan persamaan ukuran jarak Euclidian Distance dengan persamaan:

3. $(x)=,\|x-y\|=\sqrt{ } \sum(x i-y i)^{2} n i=.$.

1. Pilih secara acak objek pada masing-masing cluster sebagai kandidat medoidbaru

2. Hitung jarak setiap objek yang berada pada masing-masing cluster dengan kandidat medoid baru.

3. Hitung total simpangan (S)dengan menghitungnilai total distancebaru -total distancelama. Jika $S<0$, maka tukar objek dengan data cluster untuk membentuk sekumpulan kobjek baru sebagai medoid.

Ulangi langkah 3 sampai 5 hingga tidak terjadi perubahan medoid, sehingga didapatkan cluster beserta anggota cluster masing-masing.

\subsection{Pengumpulan Data}

Dataset yang digunakan dalam penelitian ini adalah menggunakan dataset penduduk Desa Sambirejo Timur dan data yang perlu untuk meyelesaikan penelitian ini meliputi nama kepala keluarga, pekerjaan, jumlah tanggungan, rumah milik sendiri atau sewa, dan penghasilan.

\subsection{Pembahasan}

Data-data yang diteliti adalah data kepala keluarga yang berasal dari Kantor Kepala Desa Sambirejo Timur ketika penulis melakukan obsevasi dan peneliti berusaha mengelompokan dan mengambil data yang sesuai dengan kebutuhan peneliti, sehingga menghasilkan data yang sesuai dengan tujuan peneliti. Data yang akan diolah peneliti ini dapat dilihat pada tabel 1. berikut :

Tabel 1. data Kepala Keluarga Desa Sambirejo Timur.

No. Nama Penduduk Pekerjaan Jumlah Tanggungan Rumah Penghasilan




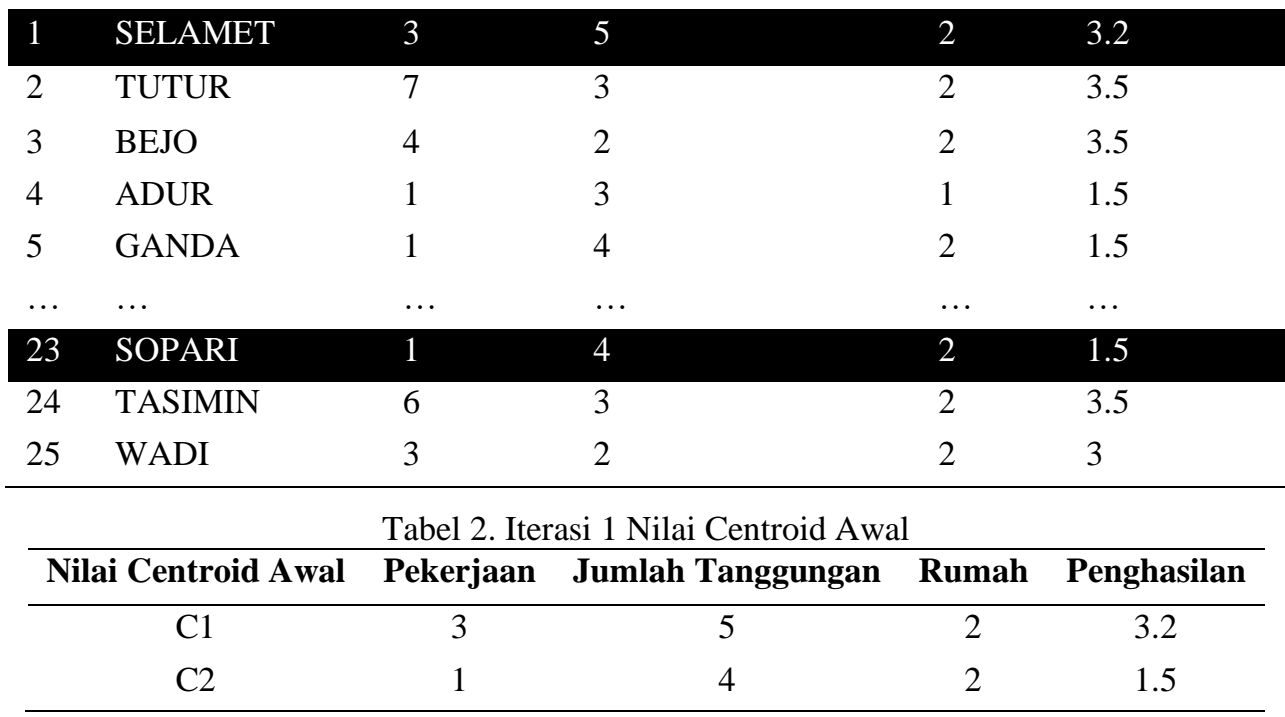

Rumus :

$$
\begin{aligned}
\text { C1 } & =\sqrt{(3-3)^{2}+(5-5)^{2}+(2-2)^{2}+(3.2-3.2)^{2}}=0 \\
& =\sqrt{(7-3)^{2}+(3-5)^{2}+(2-2)^{2}+(3.5-3.2)^{2}}=4.482186966 \\
\text { C2 } \quad & =\sqrt{(3-1)^{2}+(5-4)^{2}+(1-2)^{2}+(3.2-1.5)^{2}}=2.80891438 \\
& =\sqrt{(7-1)^{2}+(3-4)^{2}+(1-2)^{2}+(3.5-1.5)^{2}}=6.403124237
\end{aligned}
$$
sebagai berikut.

Dari hasil proses perthitungan $\mathrm{C} 1$ dan $\mathrm{C} 2$ maka, didapatkan hasil iterasi pertama untuk pengelompokan data

\begin{tabular}{cccc}
\multicolumn{4}{c}{ Tabel 3. hasil iterasi pertama. } \\
\hline Hasil Iterasi 1 & C1 & C2 & Pengelompokan \\
\hline 1 & 0 & 2.808914381 & 1 \\
2 & 4.482186966 & 6.403124237 & 1 \\
3 & 3.176476035 & 4.123105626 & 1 \\
$\ldots$ & $\ldots$ & $\ldots$ & $\ldots$ \\
23 & 2.808914381 & 0 & 1 \\
24 & 3.618010503 & 5.477225575 & 1 \\
25 & 3.006659276 & 3.201562119 & \\
\hline
\end{tabular}

Selanjutnya masuk ke langkah iterasi kedua dimana proses ini sama dengan proses iterasi pertama namun nilai centroidnya yang berubah. Dan proses iterasi kedua dapat dilihat pada Tabel 4.8 adalah sebagai berikut.

Tabel 4. Iterasi kedua.

\begin{tabular}{lllll}
\hline No. & Pekerjaan & Jumlah Tanggungan & Rumah & Penghasilan \\
\hline 1 & 3 & 5 & 2 & 3.2 \\
2 & 7 & 3 & 2 & 3.5 \\
3 & 4 & 2 & 2 & 3.5 \\
$\ldots$ & $\ldots$ & $\ldots$ & $\ldots$ & $\ldots$ \\
23 & 1 & 4 & 2 & 1.5 \\
24 & 6 & 3 & 2 & 3.5 \\
25 & 3 & 2 & 2 & 3 \\
\hline
\end{tabular}

Tabel 5. Nilai Centroid Kedua.

\begin{tabular}{ccccc}
\hline Nilai Centroid Kedua & Pekerjaan & Jumlah Tanggungan & Rumah & Penghasilan \\
\hline C1 & 7 & 3 & 2 & 3.5 \\
C2 & 3 & 2 & 2 & 3 \\
\hline
\end{tabular}

Rumus :

$$
\begin{aligned}
\mathrm{C} 1 & =\sqrt{(3-7)^{2}+(5-3)^{2}+(2-2)^{2}+(3.2-3.5)^{2}}=4.482186966 \\
& =\sqrt{(7-7)^{2}+(3-3)^{2}+(2-2)^{2}+(3.5-3.5)^{2}}=0 \\
\text { C2 } & =\sqrt{(3-3)^{2}+(5-2)^{2}+(2-2)^{2}+(3.2-3)^{2}}=3.006659276
\end{aligned}
$$




\begin{tabular}{|c|c|c|c|}
\hline \multicolumn{4}{|c|}{$=\sqrt{(7-3)^{2}+(3-2)^{2}+(2-2)^{2}+(3.5-3)^{2}}=4.153311931$} \\
\hline Hasil Iterasi 2 & C1 & $\mathrm{C2}$ & Pengelompokan \\
\hline 1 & 4.482186966 & 3.006659276 & 2 \\
\hline 2 & 0 & 4.153311931 & 1 \\
\hline 3 & 3.16227766 & 1.118033989 & 2 \\
\hline$\ldots$ & $\ldots$ & $\ldots$ & $\ldots$ \\
\hline 23 & 6.403124237 & 3.201562119 & 2 \\
\hline 24 & 1 & 3.201562119 & 1 \\
\hline 25 & 4.153311931 & 0 & 2 \\
\hline
\end{tabular}

Untuk melakukan pengelompokan warga yang kurang mampu maka dilakukan penjumlahan setiap iterasi 1 dan 2, maka dapat ditentukan nilai yang tertinggi termasuk dalam kelompok kurang mampu, oleh karena itu pihak panitia dengan cepat mengambil keputusan untuk menyalurkan bantuan yang selayaknya diterima. Maka dari hasil perhitungan iterasi 1 dan iterasi 2 didapatlah hasil pengelompokan penduduk kurang mampu dan dapat dilihat pada tabel 7. berikut.

Tabel 7. hasil pengelompokan penduduk kurang mampu

\begin{tabular}{lccccc}
\hline Nama Penduduk & Pekerjaan & Jumlah Tanggungan & Rumah & Penghasilan & Kelompok \\
\hline GANDA & 1 & 4 & 2 & 1.5 & 2 \\
ANDI & 2 & 3 & 1 & 2 & 2 \\
SIREGAR & 2 & 3 & 2 & 2 & 2 \\
ADUR & 1 & 3 & 1 & 1.5 & 2 \\
ANDONG & 1 & 4 & 2 & 1.5 & 2 \\
SOPARI & 1 & 4 & 2 & 1.5 & 2 \\
\hline
\end{tabular}

\section{KESIMPULAN}

Berdasarkan berdasarkan permasalahan yang diteliti dan pengujian yang telah dilakukan penulis, maka dapat diambil kesimpulan tentang data mining penentuan penduduk kurang mampu yang nantinya kriteria penduduk seperti apa yang layak menerima bantuan seperti dibawah ini:

1. Sistem data mining dalam menentukan penerapan data mining untuk pengelompokan penduduk kurang mampu desa sambirejo timur dengan algoritma k-medoids berdasarkan kriteria yang telah ditentukan seperti pekerjaan, Rumah, Jumlah Tanggungan dan Penghasilan.

2. Penerapan algoritma k-medoids terlebih dahulu membentuk nilai kriteria untuk dilakukan pencarian nilai setiap iterasi untuk mengetahui berapa banyak warga kurang mampu yang layak menerima bantuan yang akan diproses, setelah itu dilakukan perhitung hasil proses algoritma k-medoids.

3. Adapun faktor-faktor yang mempegaruhi dalam menentukan calon penduduk kurang mampu penerima bantuan dari pemerintah desa yaitu, pekerjaan, status rumah, banyak tanggungan dalam keluarga dan penghasilan yang didapat setiap bulannya.

\section{REFERENCES}

[1] Florin G. 2011. Data Mining. GrahaIlmu 2011. Yogyakarta.

[2] Dyang Falila Pramesti. 2017. Proses Data Mining Dalam Penemuan Pengetahuan Database. Junaedi, Hartono 2011. Yogyakarta.

[3] Mustalim. 2015. Definisi Data Mining. Astuti Fajar. Yogyakarta.

[4] Purba Yugi Trianto. 2005. Arsitektur Data Mining. Hermawan. Yogyakarta.

[5] Kaur. 2004. Algoritma K-Medoids. Dheerendra. 2014. Yogyakarta.

[6] Jogyanto Hartanto. Analisa dan Desain. 2002. Jakarta.

[7] Rosa A.s. Rekayasa Perangkat Lunak.

[8] R.H. Sianipar, Visual Basic Untuk Programmer, 2017.

[9] Abdul Kadir, Buku Pintar Pemula Programmer PHP, 2013.

[10] Kantor Kepala Desa Sambirejo Timur 2018. Jumlah Kepala Keluarga. 